\title{
Sidestream Smoke Collection Using a Harmonised Linear Smoking Machine*
}

\author{
by \\ Fiona Thomas ${ }^{l}$ and Keith G. Darrall ${ }^{1,2}$ \\ ${ }^{1}$ LGC (Teddington) Ltd, Queens Road, Teddington, Middlesex, TW11 OLY, UK \\ ${ }^{2}$ Present address: 50 Cudham Lane North, Cudham, Sevenoaks, Kent, TN14 7RA, UK
}

\section{SUMMARY}

The collection of sidestream smoke (SSS) using the "BAT fishtail chimney" method became the accepted standard, but following the harmonisation of linear and rotary smoking machines it is no longer possible to observe all parameters of the method as published. A prerequisite of any SSS collection method is that mainstream smoke (MSS) yields should not be affected. Additionally all the standard features and parameters of normal MSS collection should as far as possible remain unchanged. The previously published method and current harmonised MSS collection are not compatible mainly due to the significant increase in air-flow rate over the cigarettes that is now necessary. This study describes the use of a modified chimney that incorporates an airtight insert causing a reduction in aperture size leading to a local increase in airflow over the cigarette. The method optimises SSS collection whilst maintaining full compliance with the current International Organisation for Standardisation (ISO) Standards for MSS collection. [Beitr. Tabakforsch. Int. 20 (2002) 69-76 ]

\section{ZUSAMMENFASSUNG}

Die Sammlung des Nebenstromrauchs (NSR) mit Hilfe des BAT „Fishtail“-Kamins war die übliche Standardmethode. Nach der Harmonisierung der linearen und der RotationsAbrauchmaschinen ist es jedoch nicht länger möglich, mit dieser Methode alle Parameter wie publiziert zu untersuchen. Eine Grundvoraussetzung bei jeder Methode zur Sammlung von NSR ist es, dass die Ausbeute des Hauptstromrauchs (HSR) nicht verändert sein sollte. Außerdem sollten alle Standardmerkmale und -parameter zur Sammlung des HSR so weit wie möglich unverändert bleiben. Die früher publizierte und die gegenwärtig geltende harmo- nisierte Methode zum Sammeln des HSR sind vor allen Dingen wegen der nun notwendigen signifikant erhöhten Flussrate über den Cigaretten nicht miteinander kompatibel. Diese Studie beschreibt die Anwendung eines modifizierten Kamins mit einem luftdichten Einsatz, der den Luftdurchlaß verringert und somit zu einer lokalen Erhöhung des Luftstroms über den Cigaretten führt. Diese Methode optimiert die Sammlung von NSR unter Berücksichtigung des geltenden International Organisation for Standardisation (ISO) Standards zur Sammlung von HSR. [Beitr. Tabakforsch. Int. 20 (2002) 69-76]

\section{RESUME}

Pour recueillir la fumée du courant secondaire (CS) le «BAT fishtail» est devenu la méthode de référence, mais après l'harmonisation des machines à fumer linéaires et rotatives, il n'est plus possible d'examiner tous les paramètres comme cela a été publié. Pour chaque méthode de collecte du CS, il est indispensable que le rendement du courant principal (CP) ne soit pas affecté. De plus, toutes les caractéristiques et paramètres standards de collecte du CP devraient, dans la limite du possible, rester inchangés. La méthode publiée et la méthode actuelle harmonisée de collecte du CP ne sont pas compatibles, surtout à cause du débit d'air significativement plus élevé à travers les cigarettes, nécessaire pour la méthode actuelle. Cette étude décrit l'utilisation d'une cheminée modifiée ayant un insert étanche à l'air conduisant à une réduction de l'ouverture et ainsi à une augmentation locale du flux d'air à travers la cigarette. La méthode optimise la collecte du CS en conformité avec la Méthode Standard ISO (International Organisation for Standardisation) pour la collecte de la fumée du courant principal. [Beitr. Tabakforsch. Int. 20 (2002) 69-76] 


\section{INTRODUCTION}

Sidestream smoke (SSS) is smoke that is emitted from a cigarette, other than that drawn through the butt end (mainstream smoke [MSS]). The vast proportion of SSS arises at the burning tip (known as smoulder stream) either directly after a puff has been taken or during the inter-puff period when the cigarette is free burning. A minor fraction of the total SSS may escape through the cigarette wrapper, depending upon the porosity of the paper, and through filter tip ventilation holes if present. SSS is the major contributor to environmental tobacco smoke (ETS), and although the chemical characteristics of SSS alter fairly rapidly on dilution to form ETS, the accurate quantification of SSS is an important starting point in the study of ETS. The method of SSS collection published by British American Tobacco (BAT) in 1988 (1), colloquially known as the fishtail chimney method, has become the accepted standard method of SSS collection. This procedure uses a glass chimney with a wide fishtail-shaped bottom that is placed over the burning cigarette. A conventional Cambridge filter placed in a holder fitted at the top of the chimney collects all the particulate matter from the emitted SSS. In order to assist the passage of the smoke up the chimney, and to prevent "fallout" from the base, a pump is used to draw the smoke upwards and through the filter.

Two types of commercial smoking machine are in general use, the Filtrona linear machine and the Borgwaldt rotary machine. Prior to 1990, each of these machines delivered somewhat different MSS yields for the same cigarette. As a result of EU directives in the field of tobacco products that came into force in 1992 it was necessary to "harmonise" these two types of smoking machine, which are used in different countries of the union. To produce the harmonisation both machines received major modifications to their physical design, together with new airflow criteria for the extraction of the SSS generated.

The modifications to the Filtrona machine physically inhibit the use of the fishtail chimney as originally specified by BAT. This is because the machine now has a removable air flow baffle/diffuser placed above the cigarettes and also the maximum height between the cigarette position and the top of the machine enclosure is less than for the previous Filtrona model. In addition, the current specification for the airflow at the cigarette position is significantly higher than the original target flow rate prior to harmonisation. It is only in recent years that reports have come to light of the fishtail assembly being used again with current design of smoking machines. Recent reports of SSS determinations have been described by Labstat in Canada (2) where SSS yields are a formal requirement of British Columbia legislation, and in a paper by PERFETTI $e t$ $a l$. (3) in the USA. It is not possible to elucidate the exact methodology used in either publication due to lack of experimental detail.

The aim of this study was to develop an experimental procedure for collecting and analysing particulate matter (specifically "tar" and nicotine) from cigarette SSS, while keeping all the primary requirements of the current methodology for determining MSS yields. The procedure uses the Filtrona SM400 design of smoking machine with minimum modification of the standard ISO method for MSS determinations.

\section{Previously described procedures for SSS collection}

The BAT procedure for SSS collection utilises a glass construction, which covers the cigarette longitudinally as it is smoked. SSS is drawn up a glass tube or chimney and through a standard Cambridge filter pad. Some "tar" and nicotine will condense on the glassware before reaching the filter pad. Therefore both the residues on the inside of the glassware and the particulate matter trapped on the filter pad have to be measured and analysed and the separate yields combined to obtain total SSS yields.

Both the method described in the BAT publication and previous work (4) carried out by the Laboratory of the Government Chemist (LGC) used 3 cigarettes smoked per SSS determination. This is less than the 5 cigarettes used for standard MSS yield determinations because SSS yields of most smoke constituents are greater than MSS deliveries and a SSS yield from 5 cigarettes could overload the filter pad and may cause possible breakthrough and incomplete particulate retention. The Labstat procedure smokes a total of 4 cigarettes but the SSS filter pad is changed after two cigarettes. The first pad is extracted and analysed and the pad yield calculated on the basis of smoking two cigarettes. The second pad from cigarettes 3 and 4 is not analysed and is discarded. The glassware through which the smoke from 4 cigarettes passes is rinsed and the extract analysed. The result from this solution is calculated on the basis of smoking 4 cigarettes. The overall yields are therefore derived from a combination of smoking 2 and 4 cigarettes. The method of PERFETTI et al. omits to state how many cigarettes were smoked. It refers to two filter pads but again does not specify how these are used.

A second difference between the previous LGC method and the Labstat method concerns the measurement of the "tar" collected on the glass chimney. LGC used the classical approach of determining the gain in weight and subtracting the water and nicotine contributions obtained from GC analysis of the extract solutions. Although Labstat determines nicotine in the extract from the glassware, they do not determine its water content. Instead, a colorimetric measurement of the glassware extract is made, together with one of the corresponding extract from the SSS pad. The "tar" yield on the glassware was then computed from a straight ratio of the colorimetric absorbances of the glassware and pad solutions multiplied by the "tar" yield of the pad. This methodology was also described in the original BAT publication.

The BAT publication makes reference to a vapour phase nicotine trap, inserted after the SSS filter, but noted that a very small percentage of nicotine escaped through the filter pad. Such a trap was not used in previous LGC work (4), however PERFETTI et al. specifically made reference to this fact as a likely reason for the somewhat lower results reported by LGC in their published data. PERFETTI $e t$ al. reported that up to $15 \%$ of the total nicotine was found in this final trap. The Labstat method also includes a vapour phase trap but gives no indication of the proportion trapped. 
Table 1. Influence of flow rate on MSS and SSS yields from Kentucky 1R4F

\begin{tabular}{|c|c|c|c|c|}
\hline \multirow{2}{*}{$\begin{array}{l}\text { Parameters } \\
\text { measured }\end{array}$} & \multicolumn{4}{|c|}{ Chimney flow rate } \\
\hline & $1 \mathrm{~L} / \mathrm{min}$ & $2 \mathrm{~L} / \mathrm{min}$ & $3 \mathrm{~L} / \mathrm{min}$ & $4 \mathrm{~L} / \mathrm{min}$ \\
\hline \multicolumn{5}{|c|}{ MSS yields (mg/cig) } \\
\hline TPM & 12.74 & 12.68 & 12.69 & 12.47 \\
\hline NFDPM & 10.52 & 10.56 & 10.72 & 10.44 \\
\hline Nicotine & 0.87 & 0.86 & 0.86 & 0.88 \\
\hline \multicolumn{5}{|c|}{ SSS yields (unmodified chimney) (mg/cig) } \\
\hline Pad TPM & 41.03 & 30.77 & 24.76 & 24.29 \\
\hline PAD NFDPM & 19.86 & 21.45 & 19.50 & 19.79 \\
\hline Chimney NFDPM & 3.93 & 3.32 & 2.44 & 2.44 \\
\hline Total NFDPM & 23.79 & 24.77 & 21.94 & 22.23 \\
\hline Pad nicotine & 3.39 & 3.63 & 3.48 & 3.21 \\
\hline Chimney nicotine & 1.65 & 1.31 & 1.04 & 0.93 \\
\hline Vapour trap nicotine & 0.02 & 0.10 & 0.41 & 0.73 \\
\hline Total nicotine & 5.06 & 5.04 & 4.93 & 4.87 \\
\hline
\end{tabular}

The flow rate through the chimney is an important factor in the collection of SSS. The cross section area of the standard BAT design fishtail chimney was approximately 13.3 $\mathrm{cm}^{2}$. The current ISO Standard (5) requires an average linear flow rate of $200 \pm 30 \mathrm{~mm} / \mathrm{s}$ at the cigarette position. To achieve this flow rate across the open area at the base of the chimney requires a volume flow of over $15 \mathrm{~L} / \mathrm{min}$ up the chimney. Employing a volume flow of this magnitude is clearly impractical, particularly when using an in-line liquid trap in the system. The passage of $15 \mathrm{~L} / \mathrm{min}$ air through a liquid trap containing $25-30 \mathrm{~mL}$ of solvent is unlikely to trap a significant proportion of volatile nicotine. The nicotine would just be purged from the solvent as soon as it dissolved. Additionally, so high a flow rate for a period of perhaps $30 \mathrm{~min}$ (the time to smoke 3 cigarettes) would in practice evaporate most, if not all, of the solvent. PERFETTI et al. do not indicate the flow used in their work. Labstat method used a flow of $3 \mathrm{~L} / \mathrm{min}$ through the chimney, slightly more than the original recommendation but much less than the theoretical comparison value for current MSS smoking standards.

Smoking methodology for SSS collection should differ as little as possible from the standard ISO MSS method. The latter uses electrical coil lighters that form part of the smoking machine. However, due to the "cage" effect of the fishtail around the cigarette, in order to use these lighters the glass chimney needs to be raised temporarily during the lighting and lowered immediately after lighting. Obviously, lowering all chimneys simultaneously when multiple determinations are made requires a complex modification, and a small amount of SSS may still escape from the base of the fishtail during lighting. PERFETTI et al. do not make any reference to lighting methods. The Labstat method lights the cigarettes with an electric lighter with the chimney raised. The chimney is then lowered and a plate is positioned $6 \mathrm{~mm}$ from its base.

\section{MATERIALS AND METHOD}

\section{SSS collection}

The purpose of the baffle introduced on the harmonised Filtrona 20 channel smoking machine is to "smooth" the airflow around and above the cigarettes. In the SSS collection situation the ancillary pump controls the flow over the cigarette, the primary extract from the machine only being used to remove vapour phase. Therefore, the baffle can be removed for SSS collection without compromising either the new machine design or the SSS methodology.

The dimensions of the harmonised smoking machine determine the combined chimney length. The original LGC glassware chimneys were modified to a compatible length. The fishtail end itself was not changed, but the length of the glass tube forming the chimney was reduced so that the distance from the cigarette position to the SSS collection pad was $37.5 \mathrm{~cm}$. A Cambridge filter holder was attached by an airtight connection to the top of the chimney. A vapour phase nicotine trap containing propan-2-ol cooled in ice, was attached by a length of Tygon tubing $(55 \mathrm{~cm}$ long $\times 4.75 \mathrm{~mm}$ i.d.) from the exit side of the SSS Cambridge filter. The exit of line from the liquid trap was connected via a flow meter to a small vacuum pump. A second vapour trap, when placed in series in the flow line, did not trap any detectable nicotine, indicating that under the flow conditions used one trap was sufficient to quantitatively trap any vapour phase nicotine passing through the SSS filter. Tests showed no evidence that the cooling of a vapour phase trap in ice retained more nicotine than a similar trap at room temperature. However, the loss of solvent by evaporation into the exhaust flow was found to be significantly reduced (less than $2 \mathrm{~mL}$ being lost compared to more than $5 \mathrm{~mL}$ for traps used at room temperature). Therefore, for environmental reasons, ice cooling was used.

\section{Flow rates}

The flow rate through the chimney was measured using the inline flow meter. A series of tests were made using the reduced length, but otherwise, unmodified fishtail and a range of flow rates through the chimney from $1 \mathrm{~L} / \mathrm{min}$ to 4 $\mathrm{L} / \mathrm{min}$ using $1 \mathrm{R} 4 \mathrm{~F}$ cigarettes. It was apparent that although MSS yields were fairly constant over the flow rate range, SSS yields showed a variation in the delivery of water and nicotine. At higher flow rates less water was collected on the SSS pad and more water was carried into the vapour phase trap, presumably due to evaporation from the pad. The total nicotine yield decreased slightly with increasing airflow, although the amount of nicotine collected in the vapour phase trap increased with increasing flow-rate. The nicotine-free dry particulate matter (NFDPM) trapped on the pad showed minimal variation with flow rate. A summary of the yields obtained from these preliminary trials is given in Table 1. Further development of the method employed an extraction flow rate of $3 \mathrm{~L} / \mathrm{min}$. 


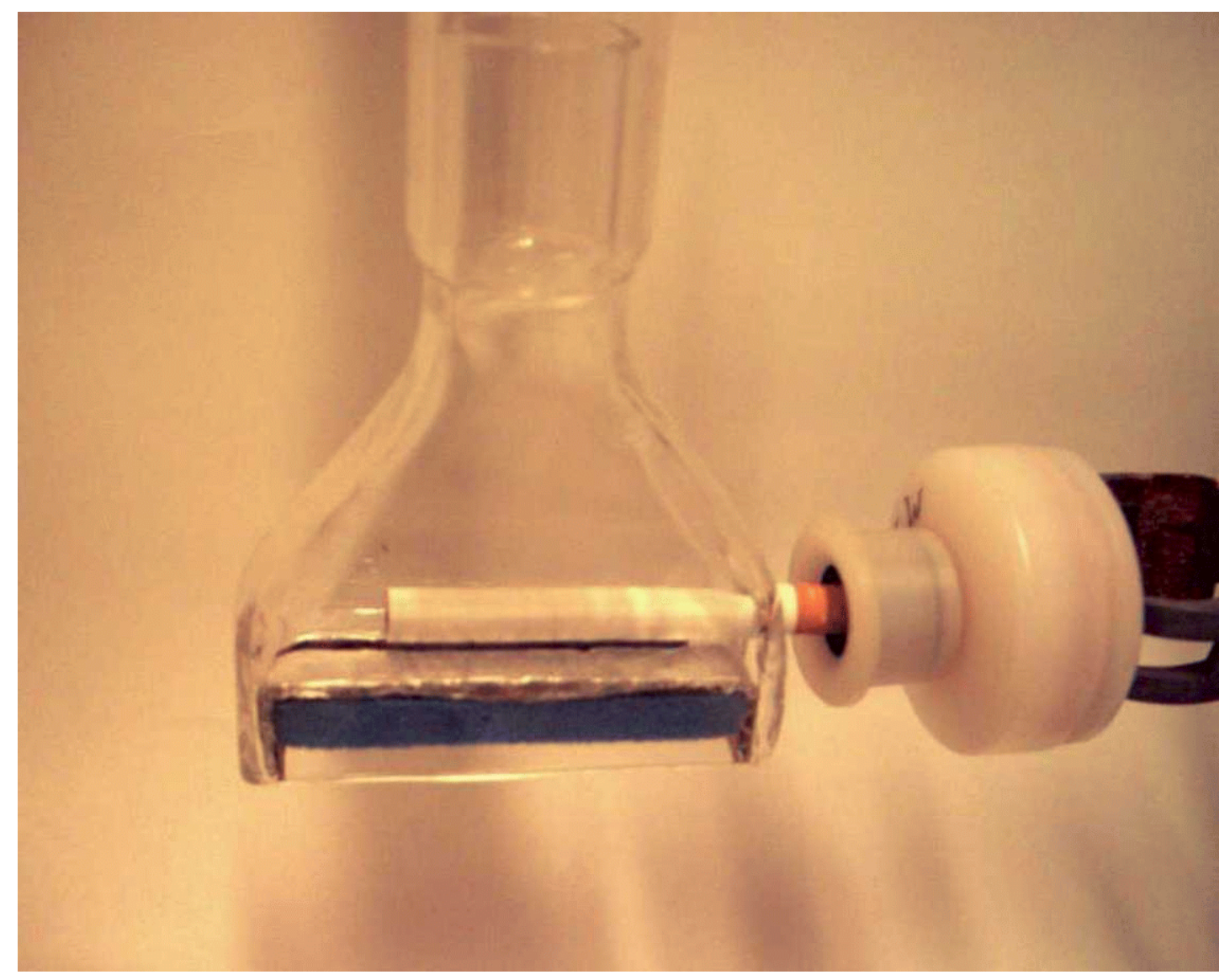

Figure 1. Photograph of the modified holder with cigarette in position

\section{Chimney insert}

In order to maintain the standard airflow conditions for the simultaneous collection of MSS it was necessary to increase the air velocity in the vicinity of the cigarette whilst keeping the overall airflow at $3 \mathrm{~L} / \mathrm{min}$. To achieve a linear flow of approximately $200 \mathrm{~mm} / \mathrm{s}$, a volume flow of $3 \mathrm{~L} / \mathrm{min}$ needs to pass through an aperture of $250 \mathrm{~mm}^{2}$ (3 $\times 10^{6} / 200 \times 60$ ). This was achieved by the design and construction of an insert made from corrugated cardboard and latex sponge. The insert was positioned directly below the cigarette immediately after it had been lit.

A piece of close texture foam sheet, $8 \mathrm{~mm}$ in thickness was glued to an area of corrugated cardboard with a width slightly less than the inside of the chimney. The cardboard was bent through 90 degrees at both ends and extended in a vertical plain for $15 \mathrm{~mm}$. The area dimensions of the foam were fractionally greater than those of inner surface of the chimney and therefore formed a seal against the glass. An aperture, $63 \mathrm{~mm} \times 4 \mathrm{~mm}$ corresponding to an area of $252 \mathrm{~mm}^{2}$, was cut centrally in the insert. The insert is so positioned in the chimney that its top surface was immediately below the cigarette when it is in position on the smoking machine. The back vertical side of the insert is used to block much of the excess area of the cut away arch of the chimney through which the cigarette protrudes. This is necessary as it was found that when only the aperture area is reduced, the airflow over the cigarette was still incorrect as much of the air is drawn in through the open vertical edge of the fishtail. The theoretical airflow could not be measured using a Schiltnecht probe (Model Thermoair 2 Anemometer, Schiltnecht Messtechnik AG, Gossau, Switzerland) normally used with the Filtrona, as the stem of this probe is wider than the fishtail. However, measurements were possible using the probe of a Lambrecht instrument (Model 642, Lambrecht GmbH, Göttingen, Germany). To make the measurement the fishtail assembly was set up on the smoking machine in the reverse orientation to normal use with the open arch side towards the operator. An insert was positioned in the fishtail and the airflow adjusted to $3 \mathrm{~L} / \mathrm{min}$. The Lambrecht probe was positioned in the fishtail where the cigarette would normally reside. Subsequent measurements on a series of insert and chimney combinations confirmed the flow in the position directly above the insert aperture was within the ISO Standard of $200 \pm 30 \mathrm{~mm} / \mathrm{s}$. The top surface of the insert was covered with aluminium foil to avoid the possibility of the cigarette burning the insert. The dimensions of the inserts were tailored individually to take account of slight variations in the contours of the different chimney walls. Insert and chimney were therefore numbered as a combination. A photograph of the insert in position in the chimney is shown in Figure 1.

\section{Application of the method to cigarettes}

Six brands of UK cigarettes were sampled, ranging in NFDPM yields from 1 to $11 \mathrm{mg} / \mathrm{cig}$, together with 4 examples 


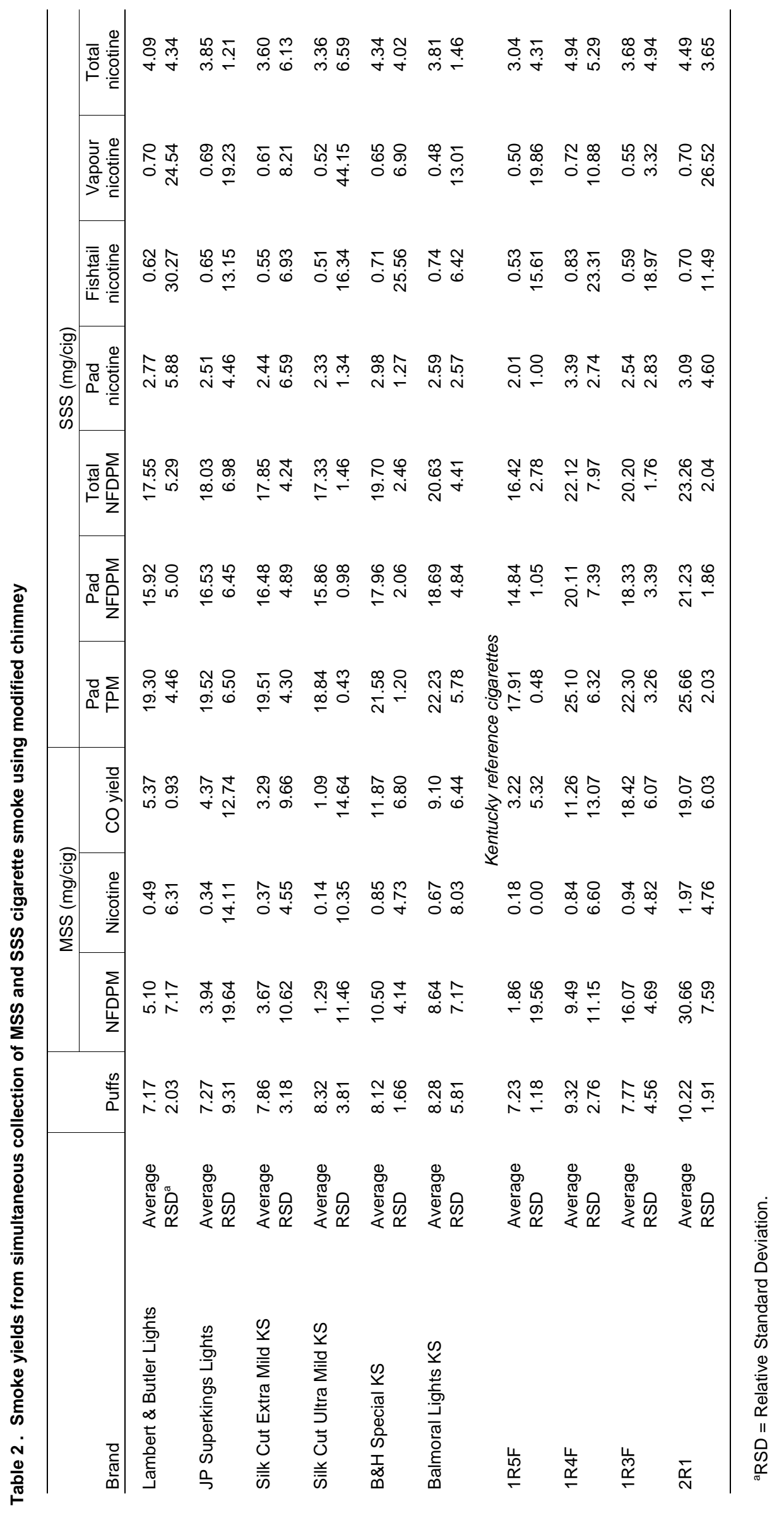


Table 3. Comparison of MSS yields using ISO and SSS methodologies

\begin{tabular}{|c|c|c|c|c|c|c|}
\hline \multirow[b]{2}{*}{ Brand } & \multirow{2}{*}{$\begin{array}{l}\text { Smoking } \\
\text { regime }^{\mathrm{a}}\end{array}$} & \multirow[b]{2}{*}{ Puff no. } & \multicolumn{4}{|c|}{ MSS yields (mg/cig) } \\
\hline & & & NFDPM & Nicotine & CO yield & TPM \\
\hline Silk Cut Ultra KS & $\begin{array}{l}\text { SSS } \\
\text { ISO } \\
\text { SSS-ISO }\end{array}$ & $\begin{array}{l}8.3 \\
8.0 \\
0.3\end{array}$ & $\begin{array}{l}1.29 \\
0.89 \\
0.40\end{array}$ & $\begin{array}{l}0.14 \\
0.12 \\
0.02\end{array}$ & $\begin{array}{r}1.09 \\
1.28 \\
-0.19\end{array}$ & $\begin{array}{l}1.43 \\
1.10 \\
0.33\end{array}$ \\
\hline Silk Cut Extra Mild KS & $\begin{array}{l}\text { SSS } \\
\text { ISO } \\
\text { SSS-ISO }\end{array}$ & $\begin{array}{r}7.9 \\
8.0 \\
-0.1\end{array}$ & $\begin{array}{l}3.67 \\
3.18 \\
0.49\end{array}$ & $\begin{array}{l}0.37 \\
0.32 \\
0.05\end{array}$ & $\begin{array}{r}3.29 \\
3.63 \\
-0.34\end{array}$ & $\begin{array}{l}4.09 \\
3.63 \\
0.46\end{array}$ \\
\hline JP Superkings Lights & $\begin{array}{l}\text { SSS } \\
\text { ISO } \\
\text { SSS-ISO }\end{array}$ & $\begin{array}{l}7.3 \\
7.2 \\
0.1\end{array}$ & $\begin{array}{l}3.94 \\
3.62 \\
0.32\end{array}$ & $\begin{array}{l}0.34 \\
0.32 \\
0.02\end{array}$ & $\begin{array}{l}4.37 \\
4.28 \\
0.09\end{array}$ & $\begin{array}{l}4.35 \\
4.12 \\
0.23\end{array}$ \\
\hline L\&B KS Lights & $\begin{array}{l}\text { SSS } \\
\text { ISO } \\
\text { SSS-ISO }\end{array}$ & $\begin{array}{l}7.2 \\
6.7 \\
0.5\end{array}$ & $\begin{array}{l}5.10 \\
5.03 \\
0.07\end{array}$ & $\begin{array}{l}0.49 \\
0.49 \\
0.0\end{array}$ & $\begin{array}{r}5.37 \\
5.82 \\
-0.45\end{array}$ & $\begin{array}{l}5.86 \\
5.82 \\
0.04\end{array}$ \\
\hline Balmoral KS Lights & $\begin{array}{l}\text { SSS } \\
\text { ISO } \\
\text { SSS-ISO }\end{array}$ & $\begin{array}{l}8.3 \\
7.9 \\
0.4\end{array}$ & $\begin{array}{l}8.64 \\
8.01 \\
0.63\end{array}$ & $\begin{array}{l}0.67 \\
0.64 \\
0.03\end{array}$ & $\begin{array}{r}9.10 \\
9.34 \\
-0.24\end{array}$ & $\begin{array}{l}9.99 \\
9.37 \\
0.62\end{array}$ \\
\hline B\&H King Size & $\begin{array}{l}\text { SSS } \\
\text { ISO } \\
\text { SSS-ISO }\end{array}$ & $\begin{array}{l}8.1 \\
7.8 \\
0.3\end{array}$ & $\begin{array}{r}10.50 \\
10.12 \\
0.38\end{array}$ & $\begin{array}{r}0.85 \\
0.86 \\
-0.01\end{array}$ & $\begin{array}{l}11.87 \\
12.67 \\
-0.80\end{array}$ & $\begin{array}{c}12.60 \\
12.60 \\
0.0\end{array}$ \\
\hline Average difference & & 0.25 & 0.38 & 0.02 & -0.32 & 0.28 \\
\hline Kentucky 1R5F & $\begin{array}{l}\text { SSS } \\
\text { ISO } \\
\text { SSS-ISO }\end{array}$ & $\begin{array}{l}7.2 \\
6.9 \\
0.3\end{array}$ & $\begin{array}{r}1.86 \\
2.03 \\
-0.17\end{array}$ & $\begin{array}{l}0.18 \\
0.15 \\
0.03\end{array}$ & $\begin{array}{r}3.22 \\
3.65 \\
-0.43\end{array}$ & $\begin{array}{r}2.19 \\
2.33 \\
-0.14\end{array}$ \\
\hline Kentucky 1R4F & $\begin{array}{l}\text { SSS } \\
\text { ISO } \\
\text { SSS-ISO }\end{array}$ & $\begin{array}{l}9.3 \\
8.8 \\
0.5\end{array}$ & $\begin{array}{l}9.49 \\
9.03 \\
0.46\end{array}$ & $\begin{array}{l}0.84 \\
0.79 \\
0.05\end{array}$ & $\begin{array}{l}11.26 \\
11.86 \\
-0.60\end{array}$ & $\begin{array}{r}11.58 \\
10.95 \\
0.63\end{array}$ \\
\hline Kentucky 1R3F & $\begin{array}{l}\text { SSS } \\
\text { ISO } \\
\text { SSS-ISO }\end{array}$ & $\begin{array}{l}7.8 \\
7.5 \\
0.3\end{array}$ & $\begin{array}{r}16.07 \\
15.68 \\
0.39\end{array}$ & $\begin{array}{l}0.94 \\
0.91 \\
0.03\end{array}$ & $\begin{array}{r}18.42 \\
18.22 \\
0.20\end{array}$ & $\begin{array}{r}21.24 \\
19.35 \\
1.89\end{array}$ \\
\hline Kentucky 2R1 & $\begin{array}{l}\text { SSS } \\
\text { ISO } \\
\text { SSS-ISO }\end{array}$ & $\begin{array}{r}10.2 \\
9.9 \\
0.3\end{array}$ & $\begin{array}{r}30.66 \\
29.53 \\
1.13\end{array}$ & $\begin{array}{l}1.97 \\
1.96 \\
0.01\end{array}$ & $\begin{array}{r}19.07 \\
18.43 \\
0.64\end{array}$ & $\begin{array}{r}38.43 \\
36.65 \\
1.78\end{array}$ \\
\hline Average difference & & 0.35 & 0.45 & 0.03 & -0.05 & 1.04 \\
\hline
\end{tabular}

aSSS = MSS yield using new SSS methodology; ISO = MSS yield using current ISO Standard Methods; SSS-ISO $=$ Difference in yields between the two methods.

of Kentucky reference cigarettes. Cigarettes were conditioned before smoking at $60 \pm 2 \% \mathrm{RH}$ and $22 \pm 1{ }^{\circ} \mathrm{C}$ for at least $48 \mathrm{~h}$ but less than $10 \mathrm{~d}(6)$. Cigarettes were lit using a hand held electric single coil lighter. The diameter of the heating area was marginally less than the internal width of the chimney and could therefore be inserted within the chimney. The cigarette was lit with the chimney in the collection position. Immediately after lighting an insert was positioned in the fishtail. One operator could make four determinations in one run by lighting each channel in turn on sequential puffs. Three cigarettes were smoked consecutively for each determination and three determinations were made for each brand. Smoking was terminated using the standard Filtrona cotton device and immediately afterwards the insert was removed and the cigarette extinguished. The pump was switched off after a further $30 \mathrm{~s}$ to allow any remaining SSS to be collected. All smoking parameters complied with current ISO Standards $(5,7)$.

\section{Sample analysis}

After smoking, the chimney and the SSS collection filter were re-weighed. The chimney was inverted and clamped over a 50 $\mathrm{mL}$ volumetric flask and propan-2-ol extract solvent run down the inside surfaces. A wash bottle was found to be the most practical method of directing the solvent. Any visible residue which was difficult to dissolve (e.g. that in the proximity of the burning butt) was removed with a small piece of filter pad soaked in solvent. This was then added to the flask. The contents were made up to volume, stoppered and mixed well. The filter pads from the MSS and SSS Cambridge filter traps were extracted using standard methodology (7).

An unfritted bubbler trap, containing $30 \mathrm{~mL}$ propan-2-ol extract solvent, was used to retain any nicotine vapour passing through the SSS Cambridge filter pad. The contents of the trap were transferred, with rinsing, to a $50 \mathrm{~mL}$ volumetric flask. The internal walls of the Tygon tubing were rinsed with propan-2-ol and added to the flask which was finally made up to volume. 
Table 4. Comparison of MSS and SSS yields for Kentucky reference cigarettes

\begin{tabular}{|c|c|c|c|c|c|c|c|c|c|}
\hline \multirow[b]{2}{*}{$\begin{array}{l}\text { Kentucky } \\
\text { reference }\end{array}$} & \multirow[b]{2}{*}{ Data set } & \multirow[b]{2}{*}{ Puffs } & \multicolumn{4}{|c|}{ MSS (mg/cig) } & \multicolumn{3}{|c|}{ SSS (mg/cig) } \\
\hline & & & TPM & NFDPM & Nicotine & CO yield & Pad TPM & $\begin{array}{c}\text { Total } \\
\text { NFDPM }\end{array}$ & $\begin{array}{c}\text { Total } \\
\text { nicotine }\end{array}$ \\
\hline \multirow[t]{3}{*}{ 1R5F } & LGC (SSS) & 7.2 & 2.2 & 1.9 & 0.18 & 3.2 & 17.9 & 16.4 & 3.04 \\
\hline & LGC (ISO) & 6.9 & 2.3 & 2.0 & 0.15 & 3.7 & * & * & * \\
\hline & Perfetti et al. & 6.7 & 2.1 & 1.7 & 0.17 & 3.7 & 19.9 & 16.2 & 4.01 \\
\hline \multirow{2}{*}{\multicolumn{2}{|c|}{$\begin{array}{l}\text { LGC(SSS) - LGC(ISO) } \\
\text { LGC(SSS) - Perfetti et al. }\end{array}$}} & 0.3 & -0.1 & -0.1 & 0.03 & -0.5 & & & \\
\hline & & 0.5 & 0.1 & 0.2 & 0.01 & -0.5 & -2.0 & 0.2 & -0.97 \\
\hline \multirow[t]{3}{*}{$1 \mathrm{R} 4 \mathrm{~F}$} & LGC (SSS) & 9.3 & 11.6 & 9.5 & 0.84 & 11.3 & 25.1 & 22.1 & 4.93 \\
\hline & LGC (ISO) & 8.8 & 11.0 & 9.0 & 0.79 & 11.9 & * & * & * \\
\hline & Perfetti et al. & 8.7 & 11.1 & 9.0 & 0.87 & 14.3 & 27.1 & 21.8 & 6.07 \\
\hline \multirow{2}{*}{\multicolumn{2}{|c|}{$\begin{array}{l}\text { LGC(SSS) - LGC(ISO) } \\
\text { LGC(SSS) - Perfetti et al. }\end{array}$}} & 0.5 & 0.6 & 0.5 & 0.05 & -0.6 & & & \\
\hline & & 0.6 & 0.5 & 0.5 & -0.03 & -3.0 & -2.0 & 0.3 & -1.14 \\
\hline \multirow[t]{3}{*}{$1 \mathrm{R} 3 \mathrm{~F}$} & LGC (SSS) & 7.8 & 21.2 & 16.1 & 0.94 & 18.4 & 22.3 & 20.2 & 3.68 \\
\hline & LGC (ISO) & 7.5 & 19.4 & 15.7 & 0.91 & 18.2 & * & * & * \\
\hline & Perfetti et al. & 7.4 & 18.0 & 14.7 & 1.04 & 15.2 & 26.6 & 23.0 & 5.01 \\
\hline \multirow{2}{*}{\multicolumn{2}{|c|}{$\begin{array}{l}\text { LGC(SSS) - LGC(ISO) } \\
\text { LGC(SSS) - Perfetti et al. }\end{array}$}} & 0.3 & 1.8 & 0.4 & 0.03 & 0.2 & & & \\
\hline & & 0.4 & 3.2 & 1.4 & -0.10 & 3.2 & -4.3 & -2.8 & -1.33 \\
\hline \multirow[t]{3}{*}{$2 \mathrm{R} 1$} & LGC (SSS) & 10.2 & 38.4 & 30.7 & 1.97 & 19.1 & 25.7 & 23.3 & 4.48 \\
\hline & LGC (ISO) & 9.9 & 36.7 & 29.5 & 1.96 & 18.4 & * & * & * \\
\hline & Perfetti et al. & 10.3 & 38.0 & 30.5 & 2.39 & 20.6 & 33.0 & 28.0 & 6.64 \\
\hline \multirow{2}{*}{\multicolumn{2}{|c|}{$\begin{array}{l}\text { LGC(SSS) - LGC(ISO) } \\
\text { LGC(SSS) - Perfetti et al. }\end{array}$}} & 0.3 & 1.7 & 1.2 & 0.01 & 0.7 & & & \\
\hline & & -0.1 & 0.4 & 0.2 & -0.42 & -1.5 & -7.3 & -4.7 & -2.16 \\
\hline \multicolumn{2}{|c|}{ Average LGC (SSS) } & 8.63 & 18.35 & 14.55 & 0.98 & 13.00 & 22.75 & 20.50 & 4.03 \\
\hline \multicolumn{2}{|c|}{ Average LGC (ISO) } & 8.28 & 17.35 & 14.05 & 0.95 & 13.05 & * & * & * \\
\hline \multicolumn{2}{|c|}{ Average Perfetti et al. } & 8.28 & 17.30 & 13.98 & 1.12 & 13.45 & 26.65 & 22.25 & 5.43 \\
\hline \multirow{2}{*}{\multicolumn{2}{|c|}{$\begin{array}{l}\text { LGC (SSS) - LGC (ISO) } \\
\text { LGC (SSS) - Perfetti et al. }\end{array}$}} & 0.35 & 1.00 & 0.50 & 0.03 & -0.05 & * & * & * \\
\hline & & 0.35 & 1.05 & 0.57 & -0.14 & -0.45 & -3.90 & -1.75 & -1.40 \\
\hline
\end{tabular}

${ }^{*}=$ No corresponding SSS measurement made.

The extracts from the SSS filter pads and chimney washings were analysed using the UV spectrophotometric method. This avoids the needs to determine water on the glassware washings, which were shown to be rather variable due to the hygroscopic nature of propan-2-ol. The extract from the SSS filter pad was diluted 50 times $(0.5$ $\mathrm{mL}$ to $25 \mathrm{~mL}$ ), and $5 \mathrm{~mL}$ of the solution from the chimney washings were diluted to $25 \mathrm{~mL}$. The spectrophotometer wavelength was set at $310 \mathrm{~nm}$, and the absorbance of each pair of solutions measured. The linearity of response up to an absorbance of 0.8 was confirmed by measurements on a series of dilutions of a SSS pad extract.

Nicotine and water contents of the extracts from the two Cambridge filters were determined by ISO gas-chromatographic methods $(8,9)$. The nicotine contents of the chimney washings and the vapour phase trap were also determined using the same instrumentation (8).

\section{RESULTS}

The results, average of three determinations, for the corresponding MSS and SSS yields of the UK brands and the Kentucky reference cigarettes are shown in Table 2. In Table 3 the puff number and MSS yields of the UK brands are compared with the corresponding values obtained during a routine survey of "tar", nicotine and carbon monoxide yields for similar sample packs.

Table 4 compares the data, both MSS and SSS, obtained in this study with that reported by PERFETTI et al. The analysis methodology closely resembles that obtained by Labstat, whose data has been published on the Internet. However, most of the Labstat data is for brands with NFDPM and nicotine yields in excess of those of the UK brands tested. Without a common brand it is not possible to offer a meaningful comparison with their results.

\section{DISCUSSION}

In general the RSD values in Table 2 indicate good reproducibility of the overall procedure for total SSS yields of NFDPM and nicotine. The average RSD's across all 10 sets of results are $3.9 \%$ and $4.2 \%$ for total NFDPM and total nicotine respectively. There were some significant variations between determinations in distribution of nicotine between the fishtail glassware and the vapour phase trap, but these even out when a total summation of the overall nicotine yield is made. The possibility exists that a small fraction of the nicotine could be absorbed by the walls of the Tygon tubing before reaching the liquid trap. 
Inspection of the data in Table 3 indicates that puff number and MSS yields of NFDPM and nicotine are marginally higher when SSS was simultaneously collected. However the increase is small (less than 5\% across all brands) and reinforces the contention that these yields are not significantly affected by the SSS methodology developed.

MSS yields for the Kentucky cigarettes are similar to the referenced data. The NFDPM SSS yields for 1R5F and 1R4F agree closely with those of PERFETTI et al., although the corresponding values for the higher yielding $1 \mathrm{R} 3 \mathrm{~F}$ and 2R1 cigarettes are significantly lower in the present work. A comparison of SSS nicotine yields indicates that substantially lower yields than those of PERFETTI et al. have been obtained in the present work. There is insufficient information available to determine how this difference arises.

The proposed method is based on smoking 3 cigarettes. The amount of TPM trapped on the SSS filter pad indicates that the SSS smoke from 4 cigarettes could be trapped without overload problems if this was deemed preferable. Results obtained thus far indicate that the reproducibility of the method is satisfactory, such that there is no immediate need to consider smoking more cigarettes.

The materials used to construct the inserts were sufficiently robust to show the principle of the device. For long-term use the cardboard component might be replaced by a material more durable. Any alternative would need to have similar properties, primarily an element of springiness to ensure the ends can grip the fishtail and prevent the insert falling out during smoking.

\section{CONCLUSIONS}

The aim of this study was to obtain an experimental procedure for collecting and analysing particulate matter (specifically for "tar" and nicotine) from cigarette SSS, without compromising the simultaneous collection of MSS yields. An integral aspect was to ensure that all the standard features and parameters of ISO MSS collection should remain unchanged. It has been demonstrated that the method developed complies with this objective to a greater extent than any method published so far. In theory and following suitable validation, the method could be applicable to the collection of other SSS particulate compounds.

Acknowledgements: This work was commissioned and funded by the UK Department of Health. The views expressed are those of the authors and not necessarily those of the Department of Health. The authors acknowledge the assistance of Dr Gillian Shine in the preparation of this paper.

\section{REFERENCES}

1. Proctor, C.J., C. Martin, J.L. Bevan, and H.F. Dymond: Evaluation of an apparatus for the collection of SS smoke; Analyst 113 (1988) 1509.

2. Determination of tar and nicotine in SS tobacco smoke, method SS-212; Prepared by Labstat Ltd under contract to Health Canada; http://www.hcsc./gc.ca/hppb/tobacco/ehd/tobacco/testmethods.

3. Perfetti, T.A., W.M. Coleman, III, and W. Smith: Determination of mainstream and sidestream cigarette smoke components for cigarettes of different tobacco types and a set of reference cigarettes; Beitr. Tabakforsch. Int. 18 (1998) 95-113.

4. Evans, W.H. and G.C. Sefton: Predictive relationships for SS smoke cigarette yields; Sci. Total Environ. 116 (1992) 269.

5. International Organisation for Standardisation: Routine analytical cigarette-smoking machine. Definitions and standard conditions; ISO 3308:2000, International Organisation for Standardisation, Geneva, 2000.

6. International Organisation for Standardisation: Tobacco and tobacco products. Atmosphere for conditioning and testing; ISO 3402:1999, International Organisation for Standardisation, Geneva, 1999.

7. International Organisation for Standardisation: Cigarettes. Determination of total and nicotine-free dry particulate matter using a routine analytical smoking machine; ISO 4387:2000, International Organisation for Standardisation, Geneva, 2000.

8. International Organisation for Standardisation: Cigarettes. Determination of nicotine in smoke condensates - Gas-chromatographic method; ISO 10315:2000, International Organisation for Standardisation, Geneva, 2000.

9. International Organisation for Standardisation: Cigarettes. Determination of water in smoke condensates. Part 1: Gas-chromatographic method; ISO 103621:1999, International Organisation for Standardisation, Geneva, 1999.

Address for correspondence:

Keith G. Darrall

50 Cudham Lane North

Cudham

Sevenoaks

Kent, TN14 7RA

$U K$ 